\title{
2 Assessing predicted age-specific breast cancer mortality rates 3 in 27 European countries by 2020
}

\author{
4 R. Clèries ${ }^{1,2}$ (10 $\cdot$ R. M. Rooney ${ }^{3} \cdot$ M. Vilardell $^{4} \cdot$ J. A. Espinàs ${ }^{1} \cdot$ T. Dyba ${ }^{3}$. \\ 5 J. M. Borras ${ }^{1,2}$
}

6 Received: 9 June 2017/ Accepted: 13 July 2017

7 (C) Federación de Sociedades Españolas de Oncología (FESEO) 2017

\section{Abstract}

AQ1 Background We assessed differences in predicted breast 10

11

A12 cancer (BC) mortality rates, across Europe, by 2020, taking into account changes in the time trends of $\mathrm{BC}$ mortality rates during the period 2000-2010.

Methods BC mortality data, for 27 European Union (EU) countries, were extracted from the World Health Organi2 zation mortality database. First, we compared BC mortality data between time periods 2000-2004 and 2006-2010 through standardized mortality ratios (SMRs) and carrying out a graphical assessment of the age-specific rates. Second, making use of the base period 2006-2012, we predicted BC mortality rates by 2020 . Finally, making use of the SMRs and the predicted data, we identified a clustering of countries, assessing differences in the time trends between the areas defined in this clustering.

Electronic supplementary material The online version of this article (doi:10.1007/s12094-017-1718-y) contains supplementary material, which is available to authorized users.

\section{R. Clèries \\ r.cleries@iconcologia.net}

1 Catalan Cancer Plan, IDIBELL, Hospital Duran i Reynals, Av. Gran Via de l'Hospitalet, 199-203-1a planta, L'Hospitalet de Llobregat, 08908 Barcelona, Catalonia, Spain

2 Department of Clinical Sciences, IDIBELL, University of Barcelona, 08907 Barcelona, Spain

3 European Commission, DG Joint Research Centre, Institute for Health and Consumer Protection, Public Health-Cancer Policy Support, 21020 Ispra, Varese, Italy

4 Section Statistics from the Department of Genetics, Microbiology and Statistics, Biology Faculty, University of Barcelona, 08028 Barcelona, Spain
Results The clustering approach identified two clusters of countries: the first cluster were countries where BC predicted mortality rates, in 2020, might slightly increase among women aged 69 and older compared with 2010 [Greece (SMR 1.01), Croatia (SMR 1.02), Latvia (SMR 1.15), Poland (SMR 1.14), Estonia (SMR 1.16), Bulgaria (SMR 1.13), Lithuania (SMR 1.03) and Slovakia (SMR 1.06)]. The second cluster was those countries where $B C$ mortality rates level off or decrease in all age groups (remaining countries). However, BC mortality rates between these clusters might diminish and converge to similar figures by 2020 .

Conclusions For the year 2020, our predictions have shown a converging pattern of $\mathrm{BC}$ mortality rates between European regions. Reducing disparities, in access to screening and treatment, could have a substantial effect in countries where a non-decreasing trend in age-specific BC mortality rates has been predicted.

Keywords Breast cancer - Europe - Mortality · Projections $\cdot$ Time trends $\cdot$ Screening

\section{Introduction}

Recent estimates have shown that breast cancer (BC) is still the most frequently reported cancer among European women [1]. However, changes in the burden of cancer mortality are expected to be observed across Europe in the short term, with BC mortality rates surpassed by those of lung cancer among young age groups [2]. These changes are related to improvements in survival due to the efficacy of treatments in parallel with earlier detection of cancer with screening [3]. Previous studies in Europe have not assessed, with precision, what amount of variability in

\begin{tabular}{|c|c|c|c|c|}
\hline & Journal : Large 12094 & Dispatch : & 15-7-2017 & Pages : \\
\hline & $\begin{array}{l}\text { Article No. : } 1718 \\
\text { MS Code : } \\
\text { CLAT-D-17-00338 }\end{array}$ & $\begin{array}{l}\square \\
\mho_{\mathrm{CP}}^{\mathrm{LE}} \\
\end{array}$ & & $\begin{array}{l}\square \text { TYPESET } \\
\longleftarrow \text { DISK }\end{array}$ \\
\hline
\end{tabular}


mortality is due to screening and/or treatment [4]. It is likely that the variation observed in the $\mathrm{BC}$ burden across Europe is attributable to various screening activities in operation, differences in diagnosis and treatment, and in the distribution of known risk factors for BC [4].

In 2003, the European Parliament (EP) adopted a Resolution (A5-0159/2003) which aims to diminish disparities in access to BC screening and treatment [5]. Since then, improvements have been observed in BC survival in some countries, notably in western and northern countries, and this has acted as an incentive for new members of the EU, and other Eastern European countries, to reduce health inequalities in access to screening and treatment, and thus reduce the gaps in $\mathrm{BC}$ mortality trends $[3,6]$.

In this study, we examined changes in the variability of BC mortality patterns in EU-27 countries, during the period 2000-2010, comparing two 5-year periods: 2000-2004 and 2006-2010. Finally, making use of the most recent trends in $\mathrm{BC}$ mortality rates, we compared the observed $\mathrm{BC}$ mortality rates, in 2010, with rates predicted for 2020 and identified two clusters of countries associated with these patterns of BC mortality.

\section{Methods}

\section{Data}

Data on BC mortality were extracted from the World Health Organization mortality database for 27 countries in Europe during the period 1990-2012 [7].

Age-specific BC mortality rates and age-standardised mortality rates (ASMRs) to the World Standard Population were calculated for all countries. In cases where agespecific data were missing, rates were estimated through linear interpolation. The latter was performed for Belgium (2000-2002), Italy (2004-2005), Portugal (2004-2006), and Poland (1997-1998). Data for Slovenia were available for 2010 and BC mortality data in 2011-2012 were estimated by applying the $\mathrm{BC}$ age-specific rates in 2010 to the population distribution in 2011-2012. Finally, BC mortality data for Slovakia in 1990 were computed as the mean of the age-specific rates between 1992 and 1993. Based on these data, we carried out four statistical models, within the Bayesian framework, assuming that the number of deaths follows a Poisson distribution. Breast cancer mortality data were arranged in eighteen 5-year age groups (from 0-4 to 85-90 years) throughout the analysis.

Data on national populations were extracted from the Eurostat Database, maintained by the European Commission [8]. The latter takes into account age-specific mortality rates and international net migration.
Changes in the $B C$ mortality rates comparing the periods 2000-2004 and 2006-2010 All the calculations assumed a Poisson distribution for the number of deaths under a Bayesian approach [9], as an extension of the classic predictive method.

Standardized mortality ratios (SMRs) were calculated to compare the risk of dying from $\mathrm{BC}$ in different periods. The ratios were computed as the number of observed $\mathrm{BC}$ deaths, in a given period, with the number of expected $\mathrm{BC}$ deaths if the age-specific death rates were the same as in another (reference) period. The SMR was used to compare the risk of death from $\mathrm{BC}$ in 2006-2010 with respect to 2000-2004. The SMRs were calculated for the whole data, for women aged 50-69 years and those 70 years or older.

Graphical assessment of the changes in the age-specific $B C$ mortality rates comparing the periods 2000-2004 and 2006-2010 Age-specific mortality rates were smoothed through an autoregressive Bayesian model imposing a temporal structure on model parameters [10]. We assumed that the number of deaths from $\mathrm{BC}$, i.e. $D$, followed a Poisson distribution, $D_{\mathrm{ip}} \sim$ Poisson $\left(\mu_{\mathrm{ip}}\right)$, where $i$ refers to the $i$ th age group, $i=\{1,2, \ldots, 17,18\} \mid\{0-4,5-$ $9, \ldots, 80-84,85-89\}$ and $p$ is the period, $p=\{1$, 2\} । $\{2000-2004,2006-2010\}$. Assuming that the expected age-specific BC mortality rate is $\lambda_{\mathrm{ip}}=\frac{\mu_{\mathrm{p}}}{Y_{\mathrm{pt}}}$, where $Y_{\mathrm{pt}}$ are the person-years at risk, we smoothed these rates through the model $\log \left(\lambda_{\mathrm{ip}}\right)=\gamma+\alpha_{\mathrm{ip}}$ where $\alpha_{\mathrm{ip}}$ are the age-specific effects and $\gamma$ an intercept which guarantees $\sum_{i} \alpha_{\text {ip }}=0$. To smooth rates, we imposed a temporal autoregressive structure of order 2 for the age effects [10] $\alpha_{\mathrm{ip}} \sim N\left(\alpha_{i-1 p}, \tau_{p}\right)$ where $\tau_{p}$ is the prior precision for which we assumed $\tau_{p} \sim \operatorname{Gamma}(0.001,0.001)$. Once the model was fitted, we simulated the posterior distribution of $\lambda_{i, 2006-2010}$ and $\lambda_{i, 2000-2004}$ and then we obtained a posterior distribution of $\theta_{i}=\frac{\lambda_{i, 2006-2010}}{\lambda_{i, 2000-2004}}$, which is the ratio of agespecific BC mortality rates between periods.

Projections of breast cancer mortality in 2020 and cluster analysis Making use of the eighteen 5-year age groups (from $0-4$ to 85-90 years), for the prediction base of 2006-2012, rates were projected to 2020 using a Bayesian log-linear age-specific model for each country [9]. Based on previous experience, the choice of a minimum prediction base length of 5 years can be considered adequate for projections [9]. Projections were made by extrapolating the rates of the model fitted to 2006-2012 to the unobserved years 2013-2020 and plugging in the age-specific population counts for those years to obtain the predicted number

\begin{tabular}{|c|c|c|c|}
\hline Journal : Large 12094 & Dispatch & $15-7-2017$ & Pages : \\
\hline Article No. : 1718 & $\square \quad \mathrm{LE}$ & & $\square$ TYPESET \\
\hline MS Code : CLAT-D-17-00338 & $\boldsymbol{V}_{\mathrm{CP}}$ & & $\boldsymbol{V}$ DISK \\
\hline
\end{tabular}



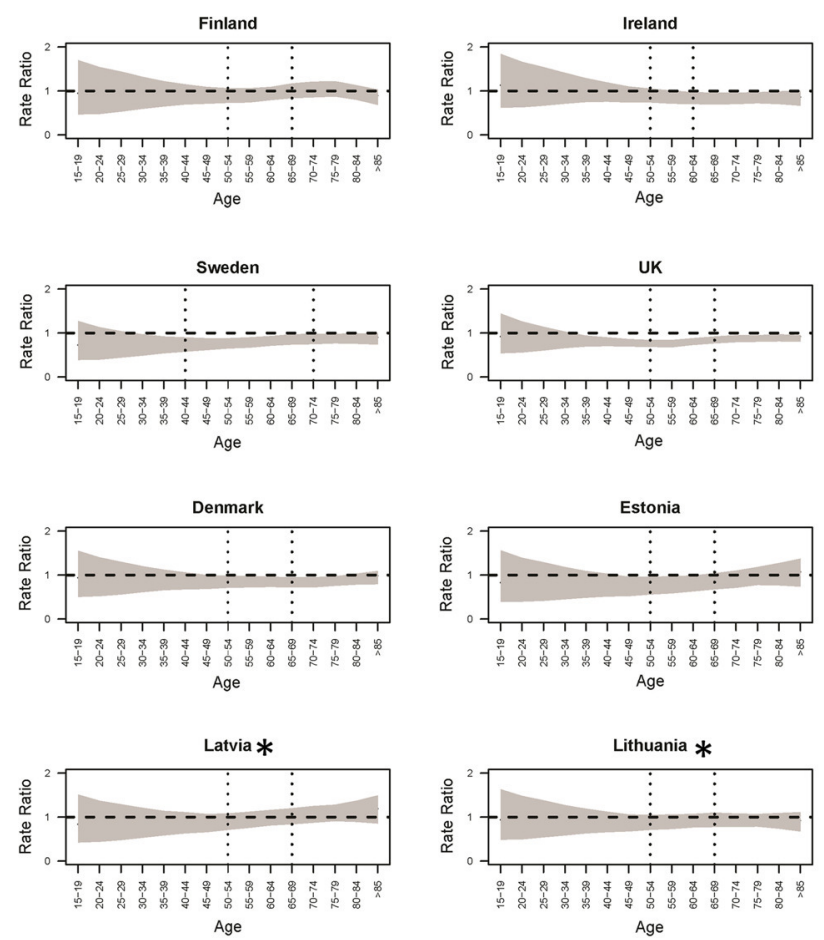

95\% Credible Interval of the Rate Ratio
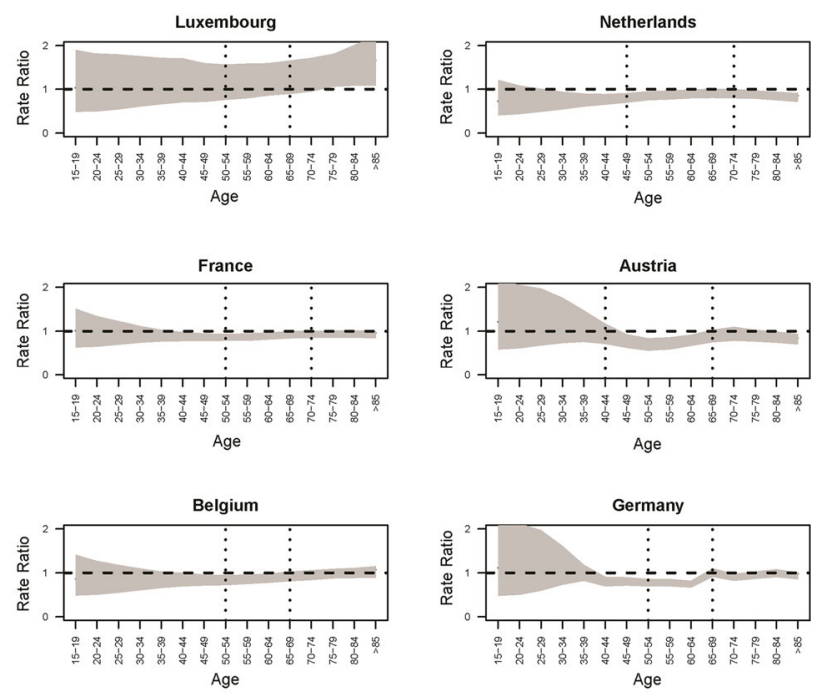

Age

\begin{abstract}
*Vertical lines: age groups considered in the screening program.
\end{abstract}
* Screening Programs were initiated after 2005. of deaths [9]. The use of these population counts is needed since these include the changes in age distribution which may affect future predictions [9, 10]. Therefore, the model took into account changes in age distribution for the period 2013-2020. These population counts were obtained from the United Nations World Population Prospects for the years 2013-2020 [11].

Finally, we assessed changes in the risk of death from BC comparing the years 2010 and 2020 by groups of countries through a weighted clustering analysis. Making use of the predicted number of BC deaths during 2020, for each country, we estimated the ASMRs during 2020 and the SMR in 2020 using as reference population that of 2010. Aggregating the ASMRs and SMRs, in a data set, during the whole study period, a hierarchical weighted clustering analysis (making use of the Ward aggregating method) was used to identify clusters of countries [12].

\section{Reporting and interpretation of results}

Based on the posterior distribution of the estimates, we calculated the $95 \%$ credible intervals $(95 \%$ CI) for SMRs and age-specific ratios. For a $95 \% \mathrm{CI}$, the value of interest SMR or age-specific ratio lies with a $95 \%$ probability in the interval. On the other hand, the $95 \%$ prediction interval of the age-specific deaths for 2020 was used for prediction purposes. All the analyses were carried out through $\mathrm{R}$ using the library INLA [13] (See supplementary material for additional Figures and $\mathrm{R}$ code).

Results are presented by grouping countries by European regions. Population screening programmes as a reference for the interpretation of the data are summarized in the Supplementary Material (see section: "The situation of BC screening programmes in the European countries considered in this study" and Table S2). The division in European regions was North, Western, Southern and Eastern European countries according to the United Nations geo scheme for Europe created by the United Nations Statistics division (https://unstats. un.org/unsd/methodology/m49/).

In the presentation of results, we marked those countries where screening activities were introduced after 2005 [5]. For those countries with screening activities, Figs. 1, 2, 3 and 4 include vertical lines corresponding to age groups included in the screening programmes. To help with the interpretation of the results presented in these figures, the start of screening activities in each country and the target age groups must be taken into account. For this purpose, see Table S1 of the Supplementary material.
174

\begin{tabular}{|l|lll|}
\hline Journal : Large 12094 & Dispatch : 15-7-2017 & Pages : 9 \\
Article No. : $\mathbf{1 7 1 8}$ & $\square$ LE & $\square$ TYPESET \\
MS Code : CLAT-D-17-00338 & $\sim_{\mathrm{CP}}$ & $\checkmark$ DISK \\
\hline
\end{tabular}



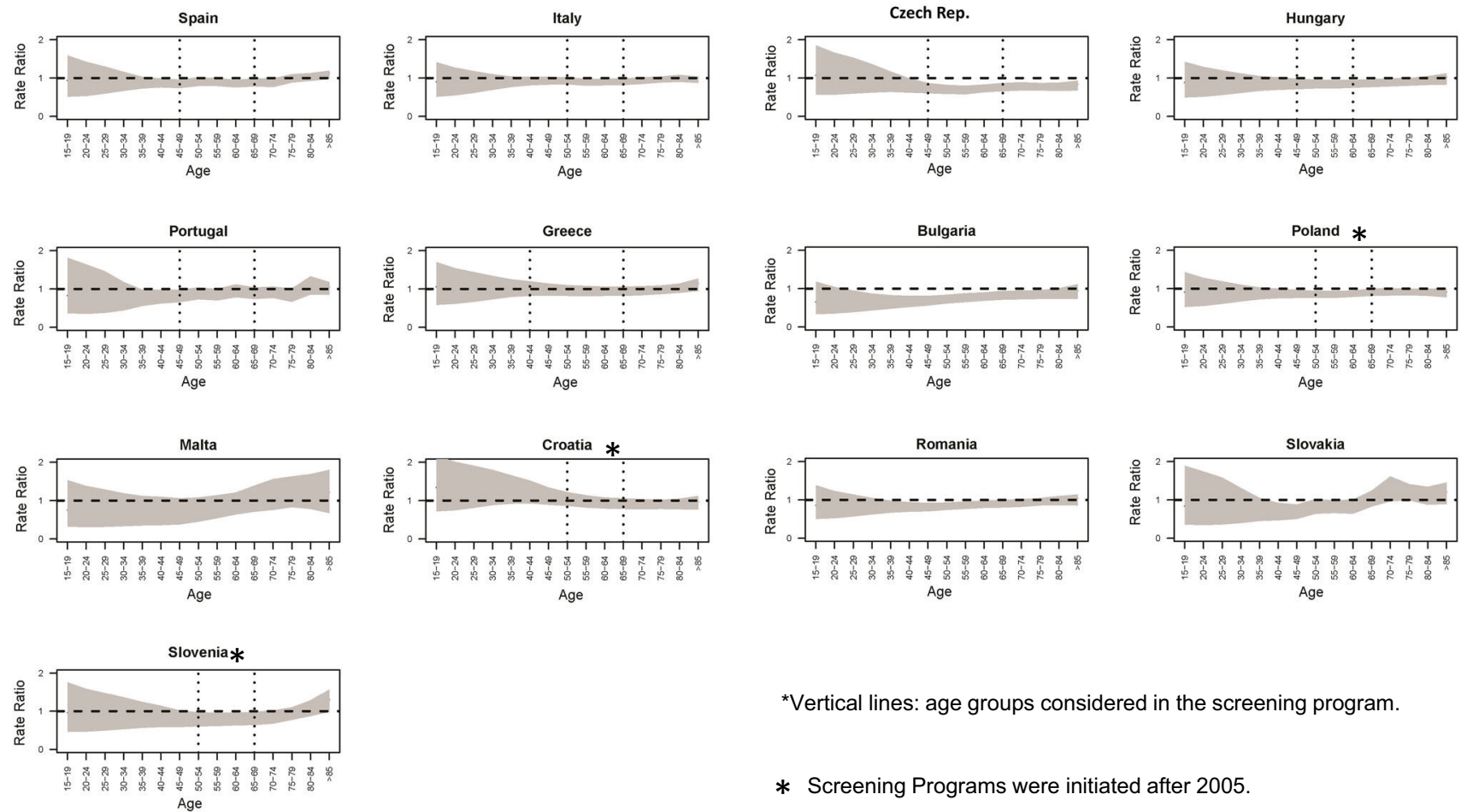

*Vertical lines: age groups considered in the screening program.

* Screening Programs were initiated after 2005.

95\% Credible Interval of the Rate Ratio

Fig. 2 Age-specific ratio of breast cancer mortality rates comparing the time periods 2000-2004 (reference) and 2006-2010: Southern and Eastern European countries

\section{Results}

Table 1 presents the SMRs for the periods 2000-2004 and 2006-2010 by the age groups 50-69 and $>69$ years. Among women aged 50-69, we found a levelling off towards a decrease in the risk of death from $\mathrm{BC}$ in the countries considered (SMRs $\leq 1)$. However, during 2006-2010 and among women aged 69 and older, there was a higher risk of death (results in bold, Table 1) in Greece $(1.15 \%)$, Croatia (1.13\%), Latvia (1.24\%), Poland $(1.11 \%)$ and Romania (1.12\%).

These results are graphically depicted in 5-year age groups in Figs. 1 and 2 and focus on the age groups included in the screening programmes which started before 2005. In those age groups where the $95 \%$ CI lies below 1, the BC mortality rate in 2006-2010 is lower than its 2000-2004 counterpart. We must interpret higher mortality in 2006-2010 with respect to 2000-2004 where the 95\% CI lies above 1 . On the other hand, if the $95 \% \mathrm{CI}$ includes 1 , it must be interpreted as no change in $\mathrm{BC}$ mortality rates between time periods. Rate ratios were clearly below 1 in most European countries (mortality rates during 2006-2010 lower than those during 2000-2004) in the age groups included in the screening programmes, with the exception of Latvia (ages 50-69), Lithuania (ages 50-69), Greece (ages 40-69 years) and Croatia (ages 50-69) (Fig. 2).

Figures 3 and 4 compare the $\mathrm{BC}$ mortality rates for 2010 and the $95 \%$ prediction interval for the age-specific $\mathrm{BC}$ mortality rates for 2020. The decreasing trend of BC mortality detected during 2000-2010 could level off by 2020 in these countries where the $95 \%$ prediction intervals for BC mortality rates in 2020 include the observed BC mortality rates in 2010 . In those age groups where the $95 \%$ prediction interval lies below the observed rates in 2010, a decrease in BC mortality rates is expected by 2020 . Given this observation, for some of the northwestern countries (Fig. 3), the predicted BC mortality rates might decrease compared with 2010. This is the case for Denmark (50-59 years), Ireland (60-69 years), the Netherlands (45-64 years), Sweden (40-64 years) and UK (50-69 years). In Eastern European countries (Fig. 4), a similar trend might occur in the Czech Republic ( $>45$ years) and Hungary (45-64 years). BC mortality rates might increase in advanced age groups (beyond 69 years of age) in Estonia, Latvia and Lithuania (see

\begin{tabular}{|l|lll|}
\hline & Journal : Large 12094 & Dispatch : 15-7-2017 & Pages : 9 \\
Article No. : $\mathbf{1 7 1 8}$ & $\square_{\mathrm{CP}}^{\text {LE }}$ & $\square_{\text {TISESET }}^{\text {TYPESE }}$ \\
\hline
\end{tabular}



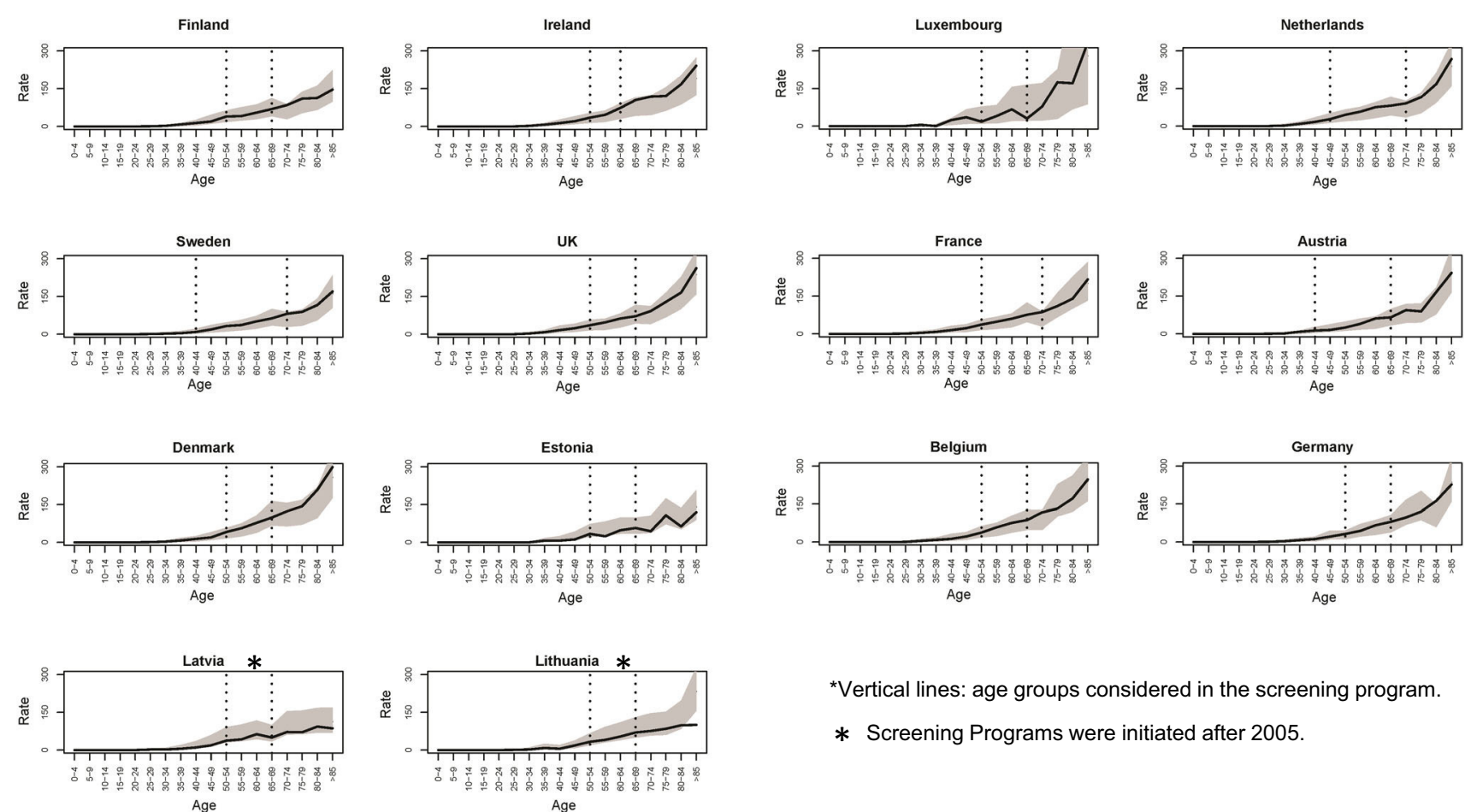

\section{*Vertical lines: age groups considered in the screening program. \\ * Screening Programs were initiated after 2005.}

95\% Prediction Interval of Breast Cancer mortality rates for 2020

Rate: Rate per 100,000 women-years

Observed Breast Cancer mortality rates in 2010

Fig. 3 Age-specific 95\% prediction intervals of breast cancer mortality rates for 2020 compared with the observed breast cancer mortality rates in 2010: Northwestern European countries

Fig. 3), and in Greece, Croatia, Bulgaria, Poland, Romania and Slovakia (see Fig. 4).

\section{Cluster analysis}

Making use of the predicted number of $\mathrm{BC}$ deaths during 2013-2020 we estimated the ASMRs for this time period. In addition, we evaluated the changes in the risk of death from BC between 2010 and 2020 calculating the SMR in 2020 with respect to 2010 (see Supplementary Table S1). We used ASMRs and SMR data in a weighted clustering analysis where our dataset included six columns: (1) ASMRs (50-69) years in 2010, (2) ASMRs (50-69) years in 2020, (3) ASMRs $>69$ years in 2010, (4) ASMRs $>69$ years in 2020, (5) SMR (50-69) years and (6) SMR $>69$ years. The clustering analysis identified two groups of countries (see Fig. 5a, where one of the clusters included Estonia, Latvia and Lithuania, Greece, Croatia, Bulgaria, Poland, Romania and Slovakia. Figure 5b, c shows that the differences in the time trend of $\mathrm{BC}$ mortality rates between these two groups of countries might disappear by 2020 since ASMRs might converge towards similar values.

\section{Discussion}

This study has shown that predicted BC mortality rates may have different trends depending on the country and European Region. Our predictions by 2020 show two patterns of BC mortality trends: (1) a non-decreasing trend mainly due to the increase in BC mortality rates from 2010 among women $>69$ years, detected in nine countries, eight out of these from Eastern Europe, and (2) a decrease towards a plateau of these rates in the remaining countries. This divergence could mean that $\mathrm{BC}$ mortality rates between European regions might diminish and converge towards similar values by 2020 . However, one must take into account that differences between countries still remain.

Several limitations should be noted. First, BC mortality trends depend on previous trends in both incidence and survival [14]; therefore, using information on the time trends of these factors could lead to better interpretation of BC mortality predictions. We interpret our results taking into account this limitation. Second, a major limitation of the model is that it assumes a stability of a large amount of

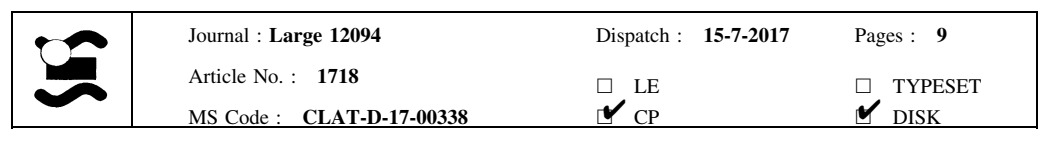


variables such as the economic situation and, related to this, universal access to the healthcare system. Taking this limitation into account differences in the targeted population that is screened could explain the differences between countries and also the impact on the $\mathrm{BC}$ mortality predictions. Changes of these variables may affect the predictions presented here.

The most recent estimates of cancer incidence and survival in Europe have shown that some Eastern European countries have the lowest BC incidence rates [4] and the lowest 5-year relative survival of $\mathrm{BC}$ among European countries [15]. In Bulgaria, Czech Republic, Poland, Slovakia, Estonia, Latvia and Lithuania, BC incidence rates rose during 1998-2007 among women aged 50-74 [4] whereas 5-year relative survival remained below the European average during a similar time period [15]. The Czech Republic shows the highest BC incidence and survival rates among these countries [15]. Therefore, our results suggest that the combined effect of $\mathrm{BC}$ diagnosis, treatment, management and organization of $\mathrm{BC}$ care, and differences in $\mathrm{BC}$ incidence between countries, may influence the variability observed in $\mathrm{BC}$ mortality rates $[1,16,17]$.

We found that, in most European countries, rate ratios were clearly below 1 when comparing $\mathrm{BC}$ mortality rates in 2006-2010 with those during 2000-2004 (reference period). In addition, advancements in breast cancer treatment, such as oestrogen therapy and adjuvant chemotherapy, and advancements in radiotherapy and surgery [1], have contributed to a decreasing trend in BC mortality rates. Selective oestrogen receptor modulators (such as tamoxifen and raloxifene) have also been assessed for primary prevention of breast cancer although their impact on mortality is likely to be limited since the chemopreventive use of these drugs has been uncommon [16]. As stated above, the implementation of organized or opportunistic breast cancer screening in many European countries is a key factor in explaining BC trends [4]. Organized mammographic screening aims to detect cancer at an earlier stage and thus reduce the incidence of advanced cancer [18] and could improve participation and equity of access [19-25]. Some other studies, however, have suggested that
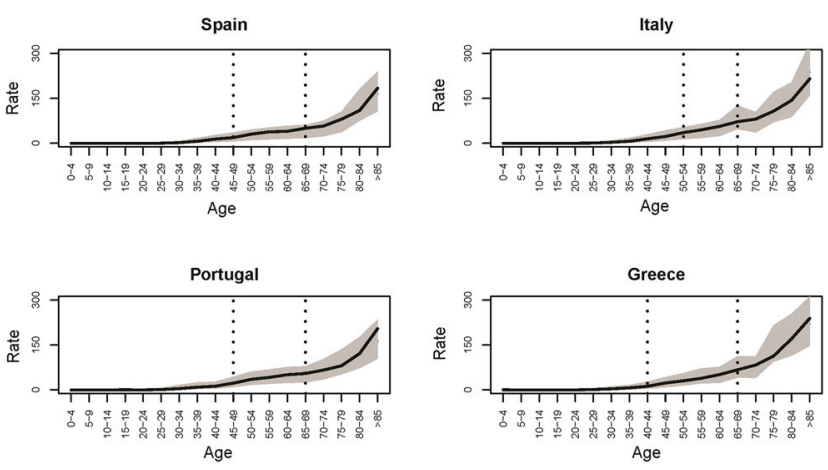

Malta

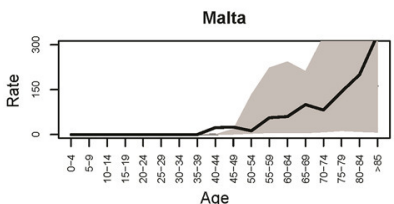

Age

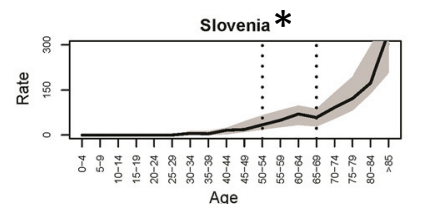

Age

95\% Prediction Interval of Breast Cancer mortality rates for 2020

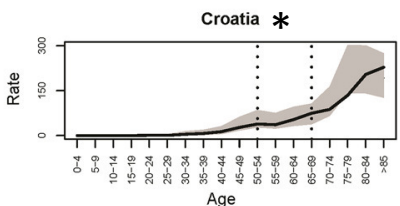

Age
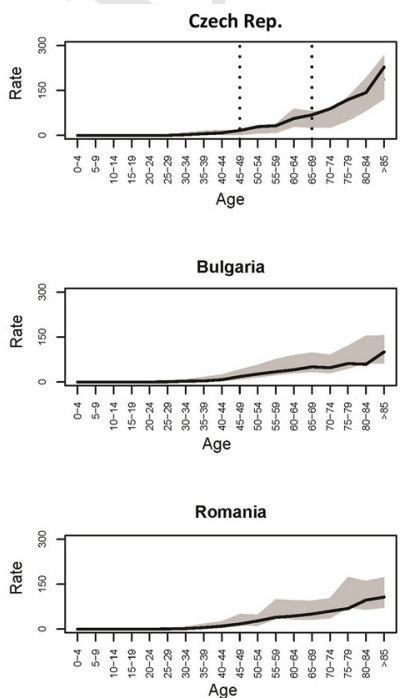

Age

Age
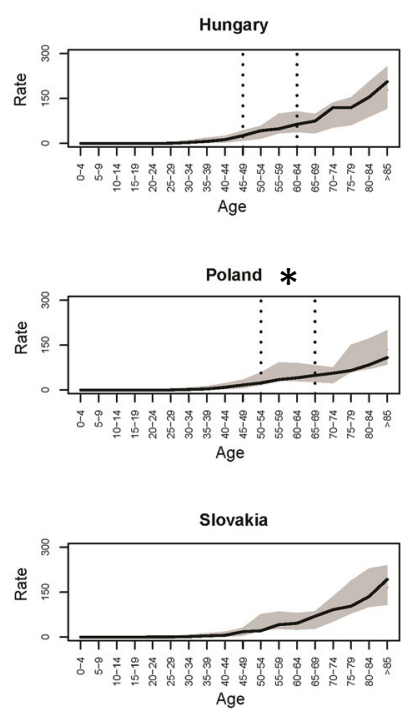

Age

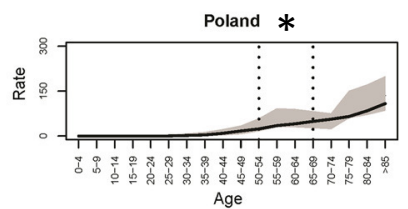

Age

*Vertical lines: age groups considered in the screening program. * Screening Programs were initiated after 2005.

Rate: Rate per 100,000 women-years

Fig. 4 Age-specific predicted rates of breast cancer mortality in 2020 compared with the observed rates in 2010: Southern and Eastern European countries

\begin{tabular}{|l|lll|}
\hline & Journal : Large 12094 & Dispatch : $\mathbf{1 5 - 7 - 2 0 1 7}$ & Pages : 9 \\
& Article No. : $\mathbf{1 7 1 8}$ & $\square$ LE & $\square$ TYPESET \\
MS Code : CLAT-D-17-00338 & $\boldsymbol{\sim}_{\mathrm{CP}}$ & $\checkmark$ DISK \\
\hline
\end{tabular}


Table 1 Standardized mortality ratios (SMR) and number of deaths from breast cancer comparing time periods 2000-2004 versus 2006-2010

\begin{tabular}{|c|c|c|c|c|c|c|c|c|c|}
\hline & \multicolumn{3}{|l|}{$50-69$ years } & \multicolumn{3}{|l|}{$>69$ years } & \multicolumn{3}{|l|}{ All ages } \\
\hline & $\begin{array}{l}2000-2004 \\
\left(N^{* *}\right)\end{array}$ & $\begin{array}{l}2006-2010 \\
\left(N^{* *}\right)\end{array}$ & SMR & $\begin{array}{l}2000-2004 \\
\left(N^{* *}\right)\end{array}$ & $\begin{array}{l}2006-2010 \\
\left(N^{* *}\right)\end{array}$ & SMR & $\begin{array}{l}2000-2004 \\
\left(N^{* *}\right)\end{array}$ & $\begin{array}{l}2006-2010 \\
\left(N^{* *}\right)\end{array}$ & SMR \\
\hline \multicolumn{10}{|c|}{ Northern and Western Europe } \\
\hline Finland & 327 & 360 & 0.91 & 394 & 442 & 0.97 & 827 & 882 & 0.93 \\
\hline Ireland & 287 & 253 & 0.70 & 272 & 336 & 1.04 & 666 & 671 & 0.81 \\
\hline Luxembourg & 34 & 31 & 0.71 & 31 & 54 & 1.02 & 82 & 93 & 0.95 \\
\hline Netherlands & 1296 & 1300 & 0.82 & 1711 & 1569 & 0.80 & 3423 & 3221 & 0.81 \\
\hline Sweden & 549 & 522 & 0.84 & 810 & 767 & 0.92 & 1521 & 1392 & 0.84 \\
\hline UK & 4590 & 3893 & 0.71 & 6690 & 6565 & 0.91 & 12,771 & 11,572 & 0.82 \\
\hline Denmark & 540 & 491 & 0.71 & 662 & 655 & 0.96 & 1334 & 1224 & 0.82 \\
\hline France* & 3977 & 4232 & 0.88 & 5611 & 6613 & 0.98 & 11,011 & 12,013 & 0.90 \\
\hline Austria & 569 & 484 & 0.80 & 967 & 881 & 0.82 & 1671 & 1501 & 0.78 \\
\hline Belgium & 945 & 855 & 0.81 & 1234 & 1371 & 0.94 & 2441 & 2431 & 0.88 \\
\hline Germany & 6956 & 5831 & 0.82 & 9293 & 10,471 & 0.95 & 18,071 & 17,721 & 0.87 \\
\hline Estonia & 134 & 92 & 0.70 & 87 & 111 & 1.11 & 275 & 222 & 0.73 \\
\hline Latvia & 202 & 183 & 0.95 & 133 & 192 & $1.24 *$ & 407 & 411 & $1.07 *$ \\
\hline Lithuania & 271 & 227 & 0.91 & 195 & 244 & 1.07 & 547 & 521 & 0.92 \\
\hline \multicolumn{10}{|c|}{ Southern Europe } \\
\hline Spain & 2080 & 2020 & 0.83 & 2850 & 3581 & 0.98 & 5676 & 6366 & 0.90 \\
\hline Italy & 4396 & 3881 & 0.83 & 5814 & 7066 & 0.97 & 11,351 & 12,144 & 0.90 \\
\hline Portugal & 581 & 623 & 1.00 & 699 & 820 & 0.95 & 1514 & 1631 & 0.91 \\
\hline Greece & 661 & 601 & 0.91 & 797 & 1232 & $1.15 *$ & 1601 & 2019 & $1.12 *$ \\
\hline Malta & 49 & 31 & 0.56 & 41 & 42 & 0.74 & 91 & 79 & 0.61 \\
\hline Croatia & 343 & 339 & 0.95 & 401 & 553 & $1.13 *$ & 846 & 971 & $1.05^{*}$ \\
\hline Slovenia & 148 & 131 & 0.82 & 191 & 247 & 0.94 & 366 & 414 & 0.94 \\
\hline \multicolumn{10}{|l|}{ Eastern Europe } \\
\hline Czech Rep. & 791 & 661 & 0.71 & 1021 & 891 & 0.73 & 1961 & 1678 & 0.71 \\
\hline Hungary & 997 & 795 & 0.73 & 1022 & 1071 & 0.87 & 2321 & 2028 & 0.88 \\
\hline Bulgaria & 543 & 543 & 0.94 & 414 & 473 & 0.98 & 1156 & 1125 & 0.89 \\
\hline Poland & 2120 & 2335 & 0.90 & 1804 & 2312 & $1.11 *$ & 4717 & 5171 & 0.99 \\
\hline Romania & 1463 & 1401 & 0.91 & 999 & 1414 & $1.12 *$ & 2976 & 3171 & 0.99 \\
\hline Slovakia & 391 & 342 & 0.81 & 357 & 391 & 0.92 & 811 & 795 & 0.89 \\
\hline
\end{tabular}

In Bold * 95\% credible interval of SMRs does not include 1, showing increasing risk between periods, ( $\left.N^{* *}\right)$ median number of BC deaths within the time period

a percentage of screening programmes associated with early detection might have less impact than treatment in reducing risk of death from this tumour [26, 27]. Uncertainty about the magnitude of the effect of screening on BC mortality reduction has been discussed elsewhere [27-30].

It is important to point out that the most recent cancer mortality trends and predictions in Europe have shown, in general, that $\mathrm{BC}$ deaths are declining towards a plateau in the EU [2]. In the short term, other cancer sites, such as lung cancer [1,2], may surpass the breast, as the leading cancer mortality site in middle-aged women. Our predictions have shown that in Estonia, Latvia and Lithuania,
Greece, Croatia, Bulgaria, Poland, Romania and Slovakia, $\mathrm{BC}$ mortality rates in 2020 might be higher than those rates in 2010. An explanation could be a rise of BC incidence combined with stabilization of $\mathrm{BC}$ survival $[4,15]$ in these countries. As a result, the predicted slight increase of $\mathrm{BC}$ mortality in these countries may lead to converging $\mathrm{BC}$ mortality rates among European countries, as our clustering analysis has shown.

A limitation of our study is that predictions were made using the last year with available data for all countries considered, i.e. 2012. The availability of the most recent estimates of future population distributions could show a

\begin{tabular}{|l|lll|} 
Journal : Large 12094 & Dispatch : 15-7-2017 & Pages : 9 \\
Article No. : $\mathbf{1 7 1 8}$ & $\square$ LE & $\square$ TYPESET \\
MS Code : CLAT-D-17-00338 & $\sim_{\text {CP }}$ & $\checkmark$ DISK \\
\hline
\end{tabular}


(b)

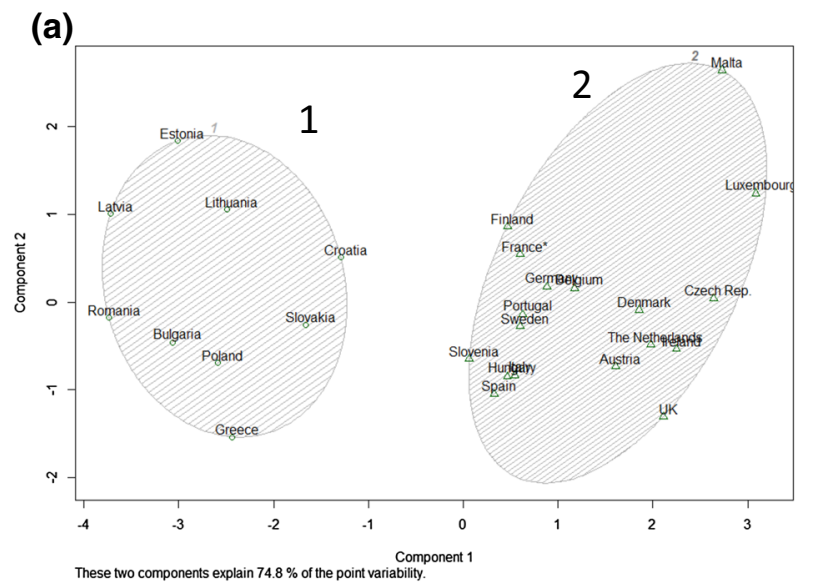

ASR: Age-Standardised Rate per 100,000 women-years

Note: Points in Panels b) and c) refer to the mean ASR of BC mortality within each cluster.

Fig. 5 a Cluster analysis using 6 variables: (1) ASMRs 50-69 years in 2010, (2) ASMRs 50-69 years in 2020, (3) ASMRs $>69$ years in 2010, (4) ASMRs $>69$ years in 2020, (5) SMR 50-69 years and (6) SMR $>69$ years. b Time trends during 1990-2020 of age-

slightly different scenario since major differences were found in women at advanced age. Large changes in population distributions, and their effect on cancer mortality, are expected to be observed when populations' prediction surpasses 10 years [9].

Diminishing disparities in access to BC screening and treatment is also the goal of the European Parliament Resolution (A5-0159/2003), mentioned in the introduction. Further development of these policies must be supported, as evidence clearly shows that such policies have a positive impact on population health.

Acknowledgements This work was supported within RTICC (cofunded by European Regional Development Fund (FEDER) - RD012/ $0036 / 0053)$. There was also support by the Agència d'Avaluació d'Universitats i Recerca (2014SGR0635).

\section{Compliance with ethical standards} any studies with human participants or animals performed by any of the authors.

Conflict of interest The funders had no role in the design of the study; the collection, analysis, or interpretation of the data; the writing of the manuscript; or the decision to submit the manuscript for publication. The authors state that there are no conflicts of interest concerning this study.
Human participants and/or animals This article does not contain

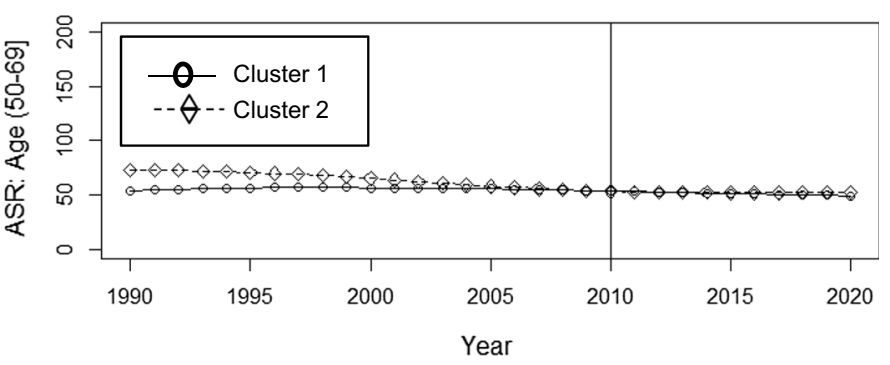

(c)

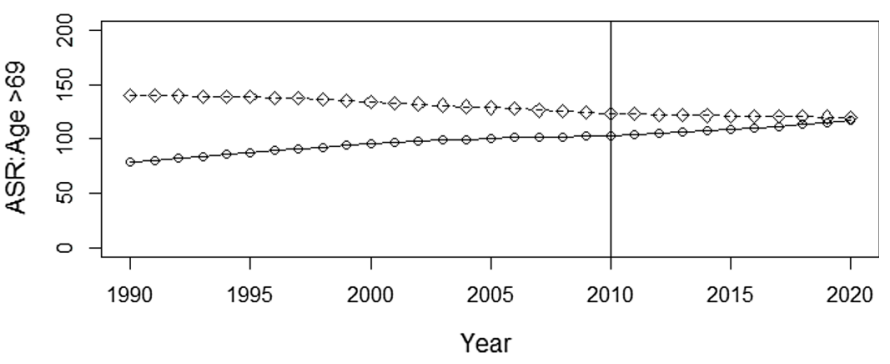

standardised mortality rates of breast cancer among women aged 50-69 years by cluster. c Time trends during 1990-2020 of agestandardised mortality rates of breast cancer among women aged $>69$ years by cluster

\section{References}

1. Ferlay J, Steliarova-Foucher E, Lortet-Tieulent J, Rosso S, Coebergh JW, Comber $\mathrm{H}$, et al. Cancer incidence and mortality patterns in Europe: estimates for 40 countries in 2012. Eur J Cancer. 2013;49(6):1374-403.

2. Malvezzi M, Bertuccio P, Rosso T, Rota M, Levi F, La Vecchia C, et al. European cancer mortality predictions for the year 2015: does lung cancer have the highest death rate in EU women? Ann Oncol. 2015;26(4):779-86.

3. Bosetti C, Bertuccio P, Levi F, Chatenoud L, Negri E, La Vecchia C. The decline in breast cancer mortality in Europe: an update (to 2009). Breast. 2012;21(1):77-82.

4. Arnold M, Karim-Kos HE, Coebergh JW, Byrnes G, Antilla A, Ferlay J, et al. Recent trends in incidence of five common cancers in 26 European countries since 1988: analysis of the European Cancer Observatory. Eur J Cancer. 2015;51(9):1164-87.

5. Jons K. On Breast Cancer in the European Union-Committee on Women's Rights and Equal Opportunities, Brussels: 2003.

6. Albreht T, McKee M, Alexe DM, Coleman MP, Martin-Moreno JM. Making progress against cancer in Europe in 2008. Eur J Cancer. 2008;44(10):1451-6.

7. World Health Organization Statistical Information System. WHO mortality database. [http://apps.who.int/healthinfo/statistics/mortality/whodpms/].

8. Eurostat Database. [http://ec.europa.eu/eurostat/web/population-demographymigration-projections/population-projections-data].

9. Clèries R, Ribes J, Buxo M, Ameijide A, Marcos-Gragera R, Galceran J, et al. Bayesian approach to predicting cancer incidence for an area without cancer registration by using cancer incidence data from nearby areas. Stat Med. 2012;31(10):978-87.

10. Clèries R, Martínez JM, Moreno V, Yasui Y, Ribes J, Borràs JM. Predicting the change in breast cancer deaths in Spain by 2019: a Bayesian approach. Epidemiology. 2013;24(3):454-60.

11. Nations U. World Population Prospects: the 2015 revision. United Nations Econ Soc Aff. 2015;XXXIII(2):1-66.

12. Murtagh F, Legendre P. Ward's hierarchical Agglomerative Clustering method: which algorithms implement ward's criterion? J Classif. 2014;31(3):274-95.

13. Martins TM, Simpson D, Lindgren F, Rue H. Bayesian computing with INLA: new features. Comput Stat Data Anal. 2009;2013(67):68-83.

\begin{tabular}{|l|lll|}
\hline & Journal : Large 12094 & Dispatch : 15-7-2017 & Pages : 9 \\
Article No. : 1718 & $\square_{\mathrm{CP}}$ & $\square$ & ${ }_{\text {TYPESET }}^{\text {TYSK }}$ \\
\hline
\end{tabular}


14. Ellis L, Woods LM, Estève J, Eloranta S, Coleman MP, Rachet B. Cancer incidence, survival and mortality: explaining the concepts. Int $\mathrm{J}$ Cancer. 2014;135(8):1774-82.

15. Sant M, Chirlaque Lopez MD, Agresti R, Sánchez Pérez MJ, Holleczek B, Bielska-Lasota M, et al. Survival of women with cancers of breast and genital organs in Europe 1999-2007: results of the EUROCARE-5 study. Eur J Cancer. 2015;51(15):2191-205

16. Smith CL, Santen RJ, Komm B, Mirkin S. Breast-related effects of selective estrogen receptor modulators and tissue-selective estrogen complexes. Breast Cancer Res. 2014;16(3):212.

17. De Angelis R, Sant M, Coleman MP, Francisci S, Baili P, Pierannunzio D, et al. Cancer survival in Europe 1999-2007 by country and age: results of EUROCARE-5-a population-based study. Lancet Oncol. 2014;15(1):23-34.

18. Palència L, Espelt A, Rodríguez-Sanz M, Puigpinós R, Pons-Vigués M, Pasarín MI, et al. Socio-economic inequalities in breast and cervical cancer screening practices in Europe: influence of the type of screening program. Int J Epidemiol. 2010;39(3):757-65

19. Espinas JA, Aliste L, Fernandez E, Argimon JM, Tresserras R, Borras JM. Narrowing the equity gap: the impact of organized versus opportunistic cancer screening in Catalonia (Spain). J Med Screen. 2011;18(2):87-90.

20. Berry D, Cronin KA, Plevritis SK, Fryback DG, Clarke L, Zelen M, et al. Effect of screening and adjuvant therapy on mortality from breast cancer. N Engl J Med. 2005;353(17):1784-92.

21. Vilaprinyo E, Puig T, Rue M. Contribution of early detection and adjuvant treatments to breast cancer mortality reduction in Catalonia, Spain. PLoS One. 2012;7(1):e30157.
22. Pavlidou E, Zafrakas M, Papadakis N, Agorastos T, Benos A. Time trends of female breast cancer mortality in Greece during 1980-2005: a population based study. Postgrad Med J. 1017;2010(86):391-4.

23. Moss SM, Wale C, Smith R, Evans A, Cuckle H, Duffy SW. Effect of mammographic screening from age 40 years on breast cancer mortality in the UK Age trial at 17 years' follow-up: a randomised controlled trial. Lancet Oncol 2015;16(9):1123-32.

24. Massat NJ, Dibden A, Parmar D, Cuzick J, Sasieni PD, Duffy SW. Impact of screening on breast cancer mortality: the UK programme 20 years on. Cancer Epidemiol Biomarkers Prev. 2015;25(3):455-62.

25. Autier P, Boniol M. Breast cancer screening: evidence of benefit depends on the method used. BMC Med. 2012;10(1):163.

26. Azim HA, de Azambuja E, Colozza M, Bines J, Piccart MJ. Long-term toxic effects of adjuvant chemotherapy in breast cancer. Ann Oncol. 2011;22(9):1939-47.

27. Bleyer $A$, Baines $C$, Miller $A B$. Impact of screening mammography on breast cancer mortality. Int J Cancer. 2015;15(138(8)):2003-12.

28. Helvie MA, Chang JT, Hendrick RE, Banerjee M. Reduction in late-stage breast cancer incidence in the mammography era: implications for overdiagnosis of invasive cancer. Cancer. 2014;120(17):2649-56.

29. European Commission. Cancer screening in the European Union. Report on the implementation of the Council Recommendation on cancer screening, 2008.

30. Martinez-Alonso M, Vilaprinyo E, Marcos-Gragera R, Rue M. Breast cance incidence and overdiagnosis in Catalonia (Spain). Breast Cancer Res. 2010;12(4):R58

\begin{tabular}{|l|lll|}
\hline Journal : Large 12094 & Dispatch : 15-7-2017 & Pages : 9 \\
Article No. : $\mathbf{1 7 1 8}$ & $\square$ LE & $\square$ TYPESET \\
& MS Code : CLAT-D-17-00338 & $\sim_{\text {CP }}$ & $\checkmark$ DISK \\
\hline
\end{tabular}

